\title{
Liberal or restricted fluid administration: are we ready for a proposal of a restricted intraoperative approach?
}

\author{
Giorgio Della Rocca, Luigi Vetrugno*, Gabriella Tripi, Cristian Deana, Federico Barbariol and Livia Pompei
}

\begin{abstract}
Background: Fluid management in the perioperative period has been extensively studied but, despite that, "the right amount" still remains uncertain. The purpose of this paper is to summarize the state of the art of intraoperative fluid approach today.

Discussion: In the current medical literature there are only heterogeneous viewpoints that gives the idea of how confusing the situation is. The approach to the intraoperative fluid management is complex and it should be based on human physiology and the current evidence.

Summary: An intraoperative restrictive fluid approach in major surgery may be beneficial while Goal-directed Therapy should be superior to the liberal fluid strategy. Finally, we propose a rational approach currently used at our institution.
\end{abstract}

Keywords: Fluid management, Liberal versus restricted, Colloid versus crystalloid, Intraoperative fluid

\section{Background}

Fluid management in the perioperative period has been extensively studied but, despite that, "the right amount" still remains uncertain. The only scientific evidence that has recently arisen is that a fluid overload (without proper guidance) seems to be a wrong strategy. Once again "devil stay in the details" and a careful differentiation between "fluid maintenance" and "fluid bolus" seems to be necessary to understand. Fluid maintenance should represent direct measurements of baseline evaporation rate from skin, airways and eventually the surgical field. In the last 50 years many studies indicated that fluid loss because of the perspiration in major abdominal surgery was high: (bodyweight +40$) \quad(\mathrm{kg}) \times 1(\mathrm{ml} / \mathrm{kg} / \mathrm{h}) \quad[1]$. Over the years this excessive fluids overutilization has been disguised and rationalized by the effect of anesthetic drugs induced hypotension, given also the reluctance of some clinicians to the use of vasopressor agents. Lamke et al. experimentally evaluated insensible perspiration and showed that it was highly overestimated [2]. The authors calculated that baseline evaporation was approximately $0.5 \mathrm{ml} / \mathrm{Kg} / \mathrm{h}$ in

\footnotetext{
* Correspondence: vetrugno.luigi@aoud.sanita.fvg.it

Dipartimento di Scienze Mediche Sperimentali e Cliniche, University of Udine, University of Udine, 33100 Udine, Italy
}

the awake adult and that it could increase to $1 \mathrm{~mL} / \mathrm{Kg} / \mathrm{h}$ at the most, during large abdominal surgery (including all bowel surgery). They also assessed that the impact of preoperative fasting on the state of the preoperative volemia was negligible [2]. Over the last few years, this circumstances gave rise to two "styles" of anesthesia management: the "liberal" and "restricted" fluid administration strategy depending on the knowledge and beliefs of that single anesthetist. But, what does "liberal approach" means compared to a "restricted one"? A standardized quantitative definition of these still remain uncertain; in the current medical literature there are only heterogeneous examples (Table 1), which give the idea of how confusing the situation is [3-6]. The purpose of this paper is to summarize the state of the art of intraoperative fluid therapy and fluid approach today.

\section{Discussion \\ Pathophysiological aspect}

The consequences of inappropriately high fluid administration may be significant, relating to liberation of atrial natriuretic peptide and an iatrogenic glycocalyx/vascular endothelial junction dysfunction, which leads to fluid shifts into the extravascular space [7]. This pathologic shift is caused by a dysfunction of the vascular barrier basically 
Table 1 Heterogeneous protocol

\begin{tabular}{lll}
\hline & Liberal & Restricted \\
\hline Holte et al. [3] & $30 \mathrm{~mL} / \mathrm{Kg} / \mathrm{h}$ & $10 \mathrm{~mL} / \mathrm{Kg} / \mathrm{h}$ \\
Holte et al. [4] & $18 \mathrm{~mL} / \mathrm{Kg} / \mathrm{h} \mathrm{RL}+$ & $5-7 \mathrm{~mL} / \mathrm{Kg} / \mathrm{h} \mathrm{RL}+$ \\
& $7 \mathrm{~mL} / \mathrm{Kg} / \mathrm{h} \mathrm{HES} \mathrm{130/0.4}$ & $7 \mathrm{~mL} / \mathrm{Kg} / \mathrm{h} \mathrm{HES} \mathrm{130/0.4}$ \\
Abraham-Nordling & $5 \mathrm{~mL} / \mathrm{Kg} / \mathrm{h} \mathrm{RL}+2 \mathrm{~mL}$ & $2 \mathrm{~mL} / \mathrm{Kg} / \mathrm{h}$ Gluc $2.5 \%$ \\
M. et al. [5] & Gluc $2.5 \%$ & \\
Lobo S. et al. [6] & $12 \mathrm{~mL} / \mathrm{Kg} / \mathrm{h} \mathrm{RL}$ & $5 \mathrm{~mL} / \mathrm{Kg} / \mathrm{h} \mathrm{RL}$ \\
\hline
\end{tabular}

because of 3 reasons: surgical manipulation, reperfusion injury and iatrogenic hypervolemia (regardless of kind of fluids administered, crystalloids or colloids). Chappell et al. described this type of fluid shifting toward the interstitial space as follow [8]:

- Type 1 disorder: represents an almost colloid-free shift of fluids and electrolytes out of the vasculature, even if the vascular barrier is intact (i.e. if large amounts of isotonic crystalloids are infused);

- Type 2 disorder: the fluids shift contains proteins close to the plasma concentration, crossing a functionally altered vascular barrier; this occurs inconstantly and is related to the type, extent, and duration of surgery and also the type of fluid used (crystalloids versus colloids).

\section{Type of fluids and patients population}

Normal saline solution (the most used crystalloid) has been used for over 50 years as an intraoperative, resuscitation and maintenance fluid; however its excessive use can lead to hyperchloremic acidosis and type I disorder. There is currently a debate regarding the morbidity associated with this condition, although its incidence is considered to be very low [9-11]. The British Consensus Guidelines on Intravenous Fluid Therapy for Adult Surgical Patients recommend the use of balanced crystalloids rather then just saline solution to avoid hypercloremic acidosis [12].

The dispute in literature about fluids, as reported in the 6S, CRYSTMAS and CHEST studies, clearly highlights the problem of the use of the right fluid in the right setting (intensive care) and for the right patient (septic patient and hemodynamic unstable intensive care unit (ICU) patients) [13-15]. These three large randomized clinical trials evaluated outcome and adverse effects of fluid resuscitation in septic patients comparing hydroxyethyl starches (HES) versus normal saline or Ringer acetate's solution: the result is that no difference in mortality has been observed between the different types of fluids (except in 6S study) [13]. In terms of kidney injury, CHEST and $6 \mathrm{~S}$ trials revealed that in HES group there is a greater risk of developing renal dysfunction; $6 \mathrm{~S}$ trial is the only one study that evaluate HES 130/0.42 (tetraspan); but the CRYSTMAS trial did not reveal any difference in terms of adverse events in both fluid groups [15]. The CRISTAL study has found instead that the use of colloids, compared to crystalloids, has resulted in a reduction of mortality at 90 days (not at 28 days) [16].

Finally, the protocols of these studies need to be discussed [17].

But the question is: are there any differences between a "relatively" healthy patient, like who is undergoing elective surgery, and a critically ill patient? In the first case the intact tight glycocalyx/vascular endothelial junction provide a proper retention of colloids, while in the second scenario the endotoxic shock or the generalized inflammatory response can lead to the disruption of the vascular barrier integrity, causing altered distribution of large molecules [18-20]. Many anesthetists use colloids solutions, mostly (HES), for blood volume expansion [21]; among these the so-called tetrastarch (a third generation hydroxyethyl starch 130/0.4) seems to have a better safety profile $[22,23]$ and there is no added risk to develop acute kidney injury in patients who receive HES during operation time [24]. In a recent review, Van Der Linden et al. [25] analyzed the safety of modern starches used during surgery: the authors concluded by arguing that the use of starches during surgery do not induce adverse renal effects, do not increase blood loss, do not require more allogenic erythrocyte transfusions and do not increase mortality [25]. But once again colloids need to be administered at the right time for the right patient; its prophylactic use to anticipate acute bleeding or to extend intravascular blood volume in a primary normovolemic patient should no longer be considered state-of-the-art. Colloids should be used to replace blood loss.

\section{Type and duration of surgery}

The type 2 disorder, as described by Chappell, opens the discussion about the type and duration of surgery (Figure 1) [8]. Now a differentiation between major and minor operations as well as abdominal versus non-abdominal surgery seems to be necessary. In a high risk surgical patient [19] undergoing an intermediate to major risk surgery some evidence based medicine support the application of a goal directed therapy (GDT), in which fluid administration is targeted on hemodynamic parameters (i.e. stroke volume) with the aim to maximize the oxygen delivery and then avoiding oxygen debt (Figures 1 and 2) [26,27]. This approach should be the best thing to do, but there are limitations that remain a major obstacle: the invasiveness of pulmonary artery catheter and transplumonary dilution technique and the poor accuracy and precision of the noninvasive devices (Vigileo - Edwards Lifesciences, Irvine, CA, USA; LiDCO - LiDCO Ltd, Cambridge, UK; ecc.) $[28,29]$. On the other hand, in moderate to high risk 


\section{Patient risk, monitoring, fluid goal and surgical time}

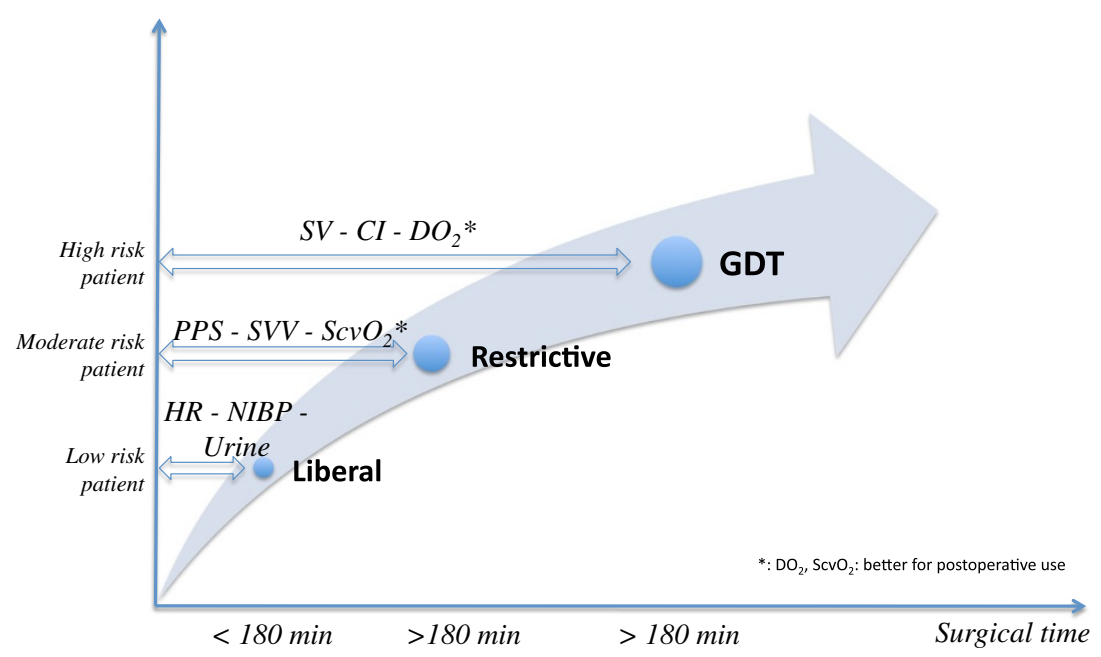

Figure 1 Patient monitoring. Hemodynamic monitoring need to be considered on the basis of patient risk, surgical type and time.

patient who is scheduled to undergo major surgery expected to last $>180$ minute, a GTD approach with the optimization of hemodynamic parameters could reduce complications $[8,30]$.

Historically, thoracic surgery has been the first married with the restricted fluid approach, but recently the emergence of new data shows that the risk of renal insufficiency after lung resection surgery is about $6-24 \%$. So, in this setting, is necessary to specify two major branch: in patients undergoing pneumonectomy the restrictive approach seems to be up-to-date but for lesser resection a GTD approach should be considered [31].

In clinical practice many studies investigated if a restrictive approach can improve surgical outcome, especially in major abdominal surgery. Lobo et al. demonstrated an improved gastrointestinal function after elective colonic resection; they also demonstrated a reduced length of hospital stay (LOS) from 9 to 6 days in the restrictive group [32]. Brandstrup demonstrated that in colo-rectal surgery a restricted management reduced post-operative complications and death [33]. Some studies in vascular patients undergoing major abdominal aortic surgery failed to identify specific superior fluid regimens. However, in this type of surgery, there is a convincing and independent association between fluid accumulation and duration of ventilation, duration of ICU stay, ICU and in-Hospital mortality and development of complications as well, such as acute respiratory distress syndrome and acute kidney

\section{Intraoperative fluid approach}

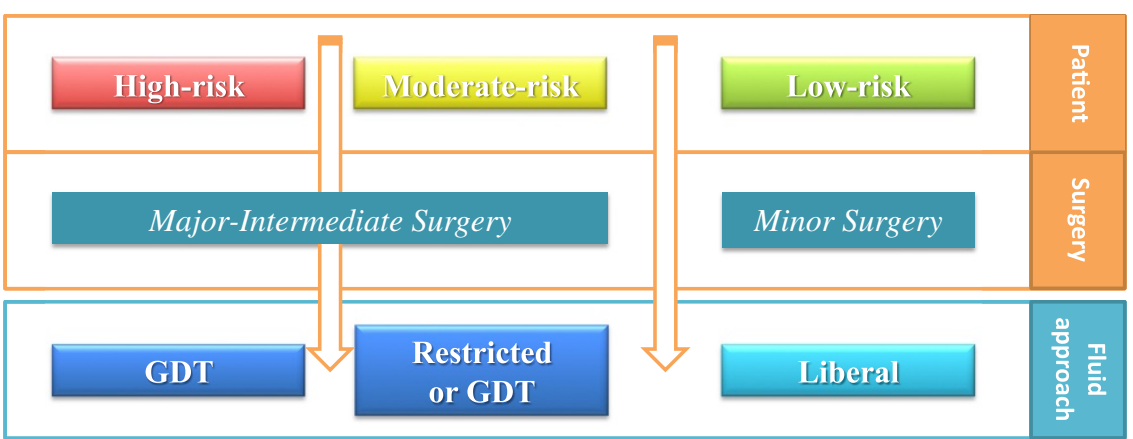

Figure 2 Perioperative fluid therapy. Intraoperative fluid therapy must take into account patient risk and type of surgery. 
injury [34]. In that context, individualized fluid administration guided by flow parameters (GDT) seems to be the best (GDT works best if it is obtained by flow algorithms) $[35,36]$. However we must keep in mind that the hemodynamic management with the GDT tends to lead to "maximization" and not "optimization", which are two different concepts; and that routine cardiovascular monitoring such as blood pressure, heart rate and urine output are not reliable predictors of intravascular fluid status and thus not a rational guide to perioperative fluid therapy.

Finally, several studies seem to suggest that in low-risk patients undergoing minor to intermediate risk surgery, liberal strategy (non restrictive) may be preferable. It reduces some postoperative complications such as nausea, vomiting, drowsiness, dizziness and length of stay [2,37-39]. In patients undergoing minor surgery, mostly in the ambulatory setting, liberal fluid administration may improve early recovery and symptoms of dehydratation (dizziness, nausea and thirst) $[40,41]$.

\section{The third fluid administration strategy in the perioperative setting: goal-directed therapy}

The GDT is an approach focused on the use of cardiac output (CO) and related parameters as end-points for fluids and drugs to optimize tissue perfusion and oxygenation by maximizing oxygen delivery (DO2). This technique was originally applied in surgical patients to achieve normal or supranormal values of $\mathrm{CO}$ and DO2 to prevent the oxygen debt caused by the perioperative increase in oxygen consumption [42]. Several clinical trials, metanalysis and reviews demonstrated its effectiveness, thus leading numerous societies to publish official guidelines that recommend its use in high-risk surgical patients [43-46].

Many tools can be used for GDT approach but the esophageal doppler (ED) monitoring (CardioQ-ODM, Deltex Medical, Chichester, West Sussex, UK) is the most supported by the literature. There are eight randomized controlled trials investigating ED-guided fluid administration: two in cardiac $[47,48]$, two in orthopedic $[49,50]$ and four in abdominal surgery [51-54]. These studies involve the use of a protocol designed to optimize the management of fluids through parameters such as stroke volume (SV) and flow time corrected (FTc), both during surgery and for the first 6-8 postoperative hours. The results show a reduced postoperative length of stay and a decrease in postoperative morbidity. As a result of these trials, EDguided fluid administration has been recommended as routine for colorectal surgeries in the UK and endorsed by Medicare and Medicaid Service [55,56].

Few studies investigated the use of other advanced hemodynamic monitoring tools (such as pulmonary and trans-pulmonary thermodilution) for intraoperative GDT, probably because of their invasiveness resulting in limited use in the operating room. Sandham et al. studied the use of the pulmonary artery catheter (PAC) on patients classified ASA (American Society of Anesthesiology) 3 and 4 but failed to demonstrate benefits regarding length of hospital stay and mortality [57].

In recent years the concept that the oxygen debt leads to an increased incidence of postoperative complications (infections, organ failure, etc.) prompted many manufacturers to develop alternative less-invasive hemodynamic devices. The most widespread of these use the uncalibrated pulse-contour analysis, a technique developed from the original algorithm described by Wesseling [58], which calculates $\mathrm{CO}$ by assessing the area under the arterial curve (i.e. Vigileo, Edwards Lifescience, Irvine, CA, USA; Pulsioflex, Pulsion Medical Germany). These instruments continually estimate $\mathrm{CO}$ and derived parameters, are easy to use and are less invasive. However, they are also less accurate and precise than those calibrated. $\mathrm{LiDCO}$ rapid (LiDCO, London, UK), is different from the others as it uses an algorithm based on the pulse power analysis [59].

Clinical trials that compared the reliability of these uncalibrated pulse contour analysis systems show conflicting results [60-63]. In a multicenter study, Salzwedel et al. have shown that performing hemodynamic optimization using ProAQT/PulsioFlex (PULSION Medical Systems SE, Munich, Germany) led to a decrease in postoperative complications in patients undergoing major abdominal surgery [64]. On the other hand Pearse and the OPTIMISE Study Group were recently unable to demonstrate any advantage in using GTD in high-risk patients undergoing major gastrointestinal surgery, compared to standard care [65]. However the inclusion of those data in an up-to-date meta-analysis (including studies from 1988 to 2013) indicates that the intervention was associated with a reduction in overall complication rates. This may be attributed to the fact that the same author, in a previous study on GDT guided by the calibrated LiDCO (LiDCO plus system; LiDCO Ltd., Cambridge, UK), showed improved outcomes after major surgery [66]. In the last study Pearse and coll. [66] used LiDCO rapid, which is an uncalibrated thermodilution technique to measure $\mathrm{CO}$, quite different from $\mathrm{LiDCO}$ plus (that uses calibrated evaluation). However that paper is the only one that enrolled and studied the highest number of patients to evaluate outcome with or without GTD (65).

Hemodynamic devices are not interchangeable and ED-guided fluid therapy has been shown to be superior to a liberal fluid strategy but not to a restrictive approach [67]. Anyway doubts have been raised on the quality of the studies supporting the ED in a recent letter [68], with the conclusion that further studies are necessary to confirm or refute this evidence. 
We have to mention also the non-invasive technologies: the Nexfin (BMEye, Edwards Life Sciences, Amsterdam, The Netherlands) and the Masimo (Masimo Corporation, Irvine, CA, USA). The Nexfin device uses a finger pneumatic cuff to evaluate a continuous non-invasive arterial pressure curve, through which it estimates the $\mathrm{CO}$ by pulse contour analysis. The Masimo provides a non-invasive estimation of the plethysmography variability index (PVI) as a consequence of variation in peripheral pulse oximetry, which has been shown to be related to pulse pressure variation (PPV). PVI is a good predictor of fluid responsiveness and has proven to be a reliable indicator in cardiac and colorectal surgery, but only in the context of a hemodynamically stable patient $[69,70]$.

What is still missing in the literature is to determine whether different instruments play different roles and if different populations of patients (ASA II-III versus IV) can benefit from these techniques. Finally, what is really important for GTD is its fundamental (patho) physiological concept: pay the "fluid debt" but also pay it "on time", within the intraoperative and first 6-8 postoperative hours.

A recent survey [71] shows that the use of GDT differs according to the medical and anesthesiological culture promoted in different settings: it is more widespread in the UK compared to the Australian/New Zealand. The majority of the respondents were involved in major abdominal and orthopedic surgery and used GDT in patients with significant comorbidities. The most significant barriers that hamper the adoption of the GDT were either a lack of availability of monitoring tools or a lack of experience with these instruments [72].

There is a long-standing debate on this manipulation of oxygen delivery in high-risk surgical patients: a therapeutic option may be not to stop at the achievement of the normalization of hemodynamic values, but to go further and aim for a "supranormal oxygen delivery", described as the therapeutic goal of a $\mathrm{DO}_{2} \mathrm{I}>600 \mathrm{ml} /$ $\mathrm{min} / \mathrm{m} 2$. This trend began in the '70s and '80s with the "milestone" of Shoemaker [73], showing that the induction of a hyperdynamic cardiovascular status was protective reducing the postoperative morbidity and mortality. However there is no lack of criticism of this approach, as it has been revised only by single-center studies with unintentional bias due to lack of blinding and different inclusion criteria and definitions. Concerning the complications, the most feared are those related to invasive monitoring and cardiac complications associated with fluid challenges and inotropes administration. Other studies failed to show any survival benefit attributable to supranormal GDT [74].

A recent metanalysis has shown that the benefit of GDT is most pronounced in patients receiving fluid and inotrope therapy to achieve a supranormal oxygen delivery target, with the use of minimally invasive cardiac monitors [75].

Perioperative optimization can be guided by lactates levels too: the development of an imbalance between oxygen delivery and oxygen consumption, define as oxygen debt, lead to lactates production above normal levels.

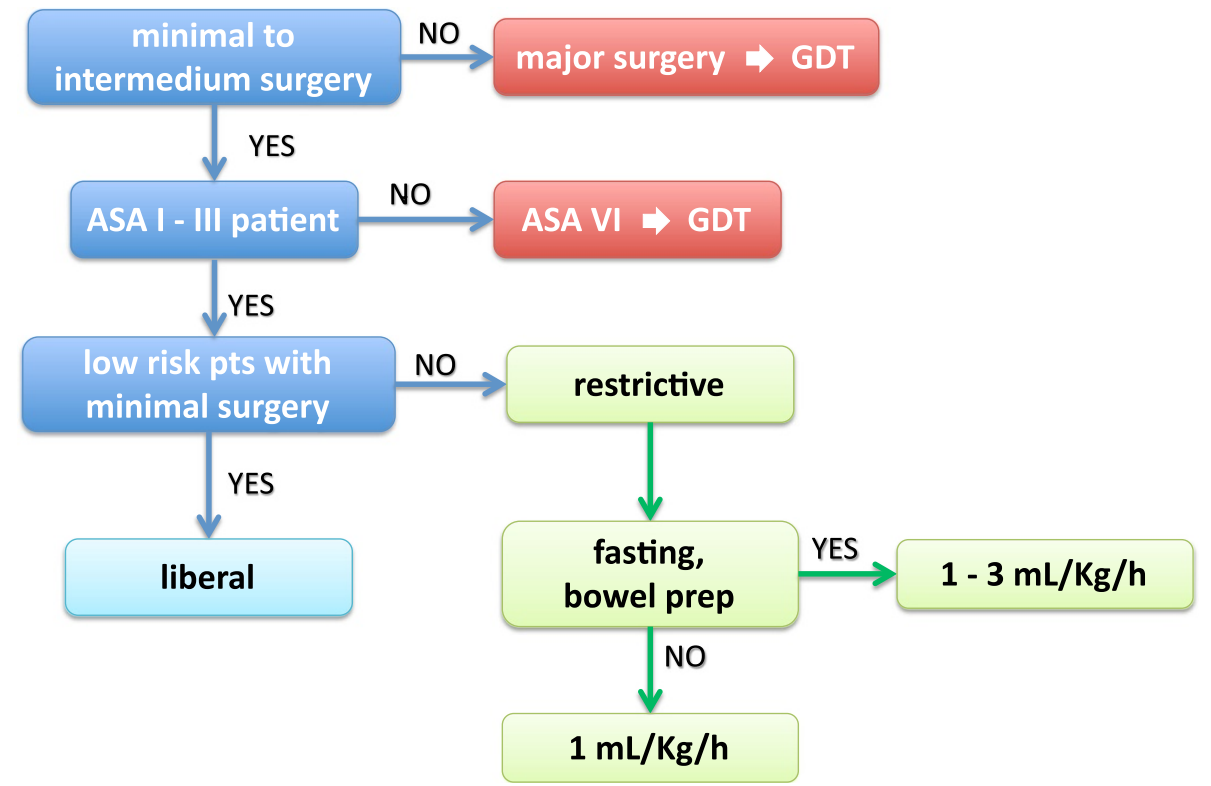

Figure 3 Fluid flow-chart. The steps reported represent a rational approach to fluid management in ASA I-III patients. 
Some studies showed that perioperative optimization targeted at lowering lactates levels can reduce post-operative complications [76].

\section{Summary}

Many studies demonstrate that an intraoperative restrictive fluid approach in major surgery improves outcome, reduces length of hospital stay, reduces anastomotic leakage and surgical site infection [5,33-41,77]. In a systematic review of 80 randomized clinical trials, Holte and Kehlet [78] recommended to avoid fluid overload in major surgical procedures. The approach to the intraoperative fluid management is complex and it should be based on human physiology and the current literature. The steps reported in Figure 3 represent a rational approach to fluid management in ASA I-III patients. The literature evidence available up to date suggests that GDT should be superior to the liberal fluid strategy; until there will be evidence that the GTD is superior or not to the restrictive fluid therapy the following approach became rational:

- During intraoperative period the anesthetist should give as many fluids as required by that single patient. Either hypovolemia, that causes organ hypoperfusion, and hypervolemia, which increases postoperative complications, should both be avoided;

- In all patients ASA I-III undergoing surgery, excluding cardiac surgery or transplantation surgery, $1 \mathrm{~mL} / \mathrm{kg} / \mathrm{h}$ of crystalloid solution should be given (if the patient did not observe the overnight fasting or did not make bowel preparation);

- In fasted patient or those who underwent bowel preparation, $1-3 \mathrm{~mL} / \mathrm{kg} / \mathrm{h}$ should be given;

- In all ASA IV patients and/or in those who are undergoing high risk surgery a GDT is strongly suggested;

- Blood loss has to be replaced only by colloids until the hemoglobin does not reach a value of $7 \mathrm{~g} / \mathrm{dL}$ (if the patient does not have cardiovascular or respiratory coexisting diseases);

- In case of diuresis monitoring, its total amount will be replaced by balanced crystalloid solutions (unless contraindicated);

- In case of hypotension soon after general anesthesia induction or during intraoperative period, it is necessary to check anesthesia level and then use vasopressors before administering fluids;

- In the postoperative period it is mandatory to restore oral hydratation and feeding as soon as possible (unless contraindicated).

\section{Abbreviations}

ASA: American society of anesthesiology physical status classification system; CO: Cardiac output; DO2: Oxygen delivery; ED: Esophageal doppler; FTc: Flow time corrected; GDT: Goal directed therapy; HES: Hydroxyethyl starch; ICU: Intensive care unit; LOS: Length of stay; PAC: Pulmonary artery catheter; PPV: Pulse pressure variation; PVI: Pleth variability index; SV: Stroke volume.

\section{Competing interests}

The authors declare that they have no competing interests.

\section{Authors' contributions}

GDR, GT and LV planned the paper and drafted the manuscript and created the flow-charts of the paper and helped to find the bibliography. LP, FB, CD helped to find the bibliography and drafted the manuscript. All authors read and approved the final manuscript.

Received: 27 January 2014 Accepted: 14 July 2014

Published: 1 August 2014

\section{References}

1. Rahbari NN, Zimmermann JB, Schmidt T, Koch M, Weigand MA, Weitz J: Meta-analysis of standard, restrictive and supplemental fluid administration in colorectal surgery. Br J Surg 2009, 96:331-341.

2. Lamke LO, Nilsson GE, Reithner HL: Water loss by evaporation from the abdominal cavity during surgery. Acta Chir Scand 1977, 143:279-284.

3. Holte K, Kristensen BB, Valentiner L, Foss NB, Husted H, Kehlet H: Liberal vs restricted fluid management in knee arthroplasty: a randomized, double blind study. Anesth Analg 2007, 105:465-474.

4. Holte K, Foss NB, Andersen J, Valentiner L, Lund C, Bie P, Kehlet H: Liberal or restricted fluid administration in fast-track colonic surgery: a randomized, double-blind study. Br J Anaesth 2007, 99:500-508.

5. Abraham-Nordling M, Hjern F, Pollack J, Prytz M, Borg T, Kressner U: Randomized clinical trial of fluid restriction in colorectal surgery. $\mathrm{Br} J$ Surg 2012, 99:186-191.

6. Lobo SM, Ronchi LS, Oliveira NE, Brandão PG, Froes A, Cunrath GS, Nishiyama KG, Netinho JG, Lobo FR: Restrictive strategy of intraoperative fluid maintenance during optimization of oxygen delivery decreases major complications after high-risk surgery. Crit Care 2011, 15(5):R226.

7. Bruegger D, Jacob M, Rehm M, Loetsch M, Welsch U, Conzen P, Becker BF: Atrial natriuretic peptide induces shedding of endothelial glycocalyx in coronary vascular bed of guinea pig hearts. Am J Physiol Heart Circ Physiol 2005, 289(5):H1933-H1939.

8. Chappell D, Jacob M, Hofmann-Kiefer K, Conzen P, Rehm M: A rational approach to perioperative fluid management. Anesthesiology 2008, 109(4):723-740.

9. Liu B, Finfer S: Intravenous fluids in adults undergoing surgery. $\mathrm{Br}$ Med J 2009, 339:3-4

10. Handy JM, Soni N: Physiological effects of hyperchloraemia and acidosis. Br J Anaesth 2008, 101(2):141-150.

11. Guidet B, Soni N, Della Rocca G, Kozek S, Vallet B, Annane D, James M: A balanced view of balanced solutions. Crit Care 2010, 14(5):325.

12. Soni N: British consensus guidelines on intravenous fluid therapy for adult surgical patients (GIFTASUP). Anaesthesia 2009, 64(3):235-238.

13. Myburgh JA, Finfer S, Bellomo R, Billot L, Cass A, Gattas D, Glass P, Lipman J, Liu B, McArthur C, McGuinness S, Rajbhandari D, Taylor CB, Webb SA: Hydroxyethyl starch or saline for fluid resuscitation in intensive care (CHEST trial). N Engl J Med 2012, 367(20):1901-1911.

14. Perner A, Haase N, Guttormsen AB, Tenhunen J, Klemenzson G, Aneman A Madsen KR, Møller MH, Elkjær JM, Poulsen LM, Bendtsen A, Winding R, Steensen M, Berezowicz P, Søe-Jensen P, Bestle M, Strand K, Wiis J, White JO, Thornberg KJ, Quist L, Nielsen J, Andersen LH, Holst LB, Thormar K, Kjældgaard AL, Fabritius ML, Mondrup F, Pott FC, Møller TP, et al: Hydroxyethyl starch 130/0.42 versus ringer's acetate in severe sepsis (6S trial). N Engl J Med 2012, 367(2):124-134.

15. Guidet B, Martinet $O$, Boulain T, Philippart F, Poussel JF, Maizel J, Forceville $X$, Feissel M, Hasselmann M, Heininger A, Van Aken H: Assessment of hemodynamic efficacy and safety of $6 \%$ hydroxyethylstarch $130 / 0.4$ vs $0.9 \% \mathrm{NaCl}$ fluid replacement in patients with severe sepsis: the CRYSTMAS study. Crit Care 2012, 16(3):R94.

16. Annane D, Siami $S$, Jaber $S$, Martin C, Elatrous $S$, Declère AD, Preiser JC, Outin H, Troché G, Charpentier C, Trouillet JL, Kimmoun A, Forceville X, Darmon M, Lesur O, Reignier J, Abroug F, Berger P, Clec'h C, Cousson J, Thibault L, Chevret S, CRISTAL Investigators: Effects of fluid resuscitation with colloids vs. crystalloids onmortality in critically ill patients 
presenting with hypovolemic shock. The CRISTAL randomized trial. JAMA 2013, 310(17):1809-1817

17. Meybohm P, Aken HV, Gasperi AD, Hert SD, Rocca GD, Girbes AR, Gombotz H, Guidet B, Hasibeder W, Hollmann MW, Ince C, Jacob M, Kranke P, KozekLangenecker S, Loer SA, Martin C, Siegemund M, Wunder C, Zacharowski K: Re-evaluating currently available data and suggestions for planning randomised controlled studies regarding the use of hydroxyethyl starch in critically ill patients - a multidisciplinary statement. Crit Care 2013, 17(4):R166.

18. Marechal X, Favory R, Joulin O, Montaigne D, Hassoun S, Decoster B, Zerimech F, Neviere R: Endothelial glycocalyx damage during endotoxiemia coincides with microcirculatory dysfunction and vascular oxidative stress. Shock 2008, 29:572-576.

19. Steppan J, Hofer S, Funke B, Brenner T, Henrich M, Martin E, Weitz J, Hofmann U, Weigand MA: Sepsis and major abdominal surgery lead to flaking of the endothelial glycocalyx. J Surg Res 2011, 165(1):136-141.

20. Bansch P, Nelson A, Ohlsson T, Bentzer P: Effect of charge on micorvascular permeability in early experimental sepsis in the rat. Microvasc Res 2011, 82(3):339-345.

21. Singer M: Management of fluid balance: a European perspective. Curr Opin Anaesthesiol 2012, 25(1):96-101.

22. Jungheinrich C, Neff TA: Pharmacokinetics of hydroxyethylstarch. Clin Pharmacokinet 2005, 44(7):681-699.

23. Westphal M, James MF, Kozek-Langenecker S, Stocker R, Guidet B, Van Aken $H$ : Hydroxyethyl starches: different products - different effects. Anesthesiology 2009, 111(1):187-202.

24. Endo A, Uchino S, Iwai K, Saito K, Sanui M, Takinami M, Uezono S: Intraoperative hydroxyethyl starch $70 / 0.5$ is not related to acute kidney injury in surgical patients: retrospective cohort study. Anesth Analg 2012 115(6):1309-1314.

25. Van DerLinden $P$, James M, Mythen M, Weiskopf RB: Safety of modern starches used during surgery. Anesth Analg 2013, 116:35-48.

26. Corcoran T, Rhodes JE, Clarke S, Myles PS, Ho KM: Perioperative fluid management strategies in major surgery: a stratified meta-analysis. Anesth Analg 2012, 114(3):640-651.

27. Cecconi M, Fasano N, Langiano N, Divella M, Costa MG, Rhodes A, Della RG: Goal-directed haemodynamic therapy during elective total hip arthroplasty under regional anaesthesia. Crit Care 2011, 15(3):R132.

28. Polanczyk CA, Rohde LE, Goldman L, Cook EF, Thomas EJ, Marcantonio ER, Mangione CM, Lee TH: Right heart catheterization and cardiac complications in patients undergoing noncardiac surgery: an observational study. JAMA 2001, 286(3):309-314.

29. Vincent JL, Rhodes A, Perel A, Martin GS, Della Rocca G, Vallet B, Pinsky MR, Hofer CK, Teboul JL, De Boode WP, Scolletta S, Vieillard-Baron A, De Backer D, Walley KR, Maggiorini M, Singer M: Clinical review: update on hemodynamic monitoring - a consensus of 16. Crit Care 2011, 15(4):229.

30. Holte K: Pathophysiology and clinical implications of perioperative fluid management in elective surgery. Dan Med Bull 2010, 57(7):B4156.

31. Assaad S, Popescu W, Perrino A: Fluid management in thoracic surgery. Curr Opin Anaesthesiol 2013, 26(1):31-39.

32. Lobo DN, Bostock KA, Neal KR, Perkins AC, Rowlands BJ, Allison SP: Effect of salt and water balance on recovery of gastrointestinal function after elective colonic resection: a randomised controlled trial. Lancet 2002, 359(9329)):1812-1818.

33. Brandstrup B, Tønnesen $H$, Beier-Holgersen $R$, Hjortsø $E$, Ørding $H$, Lindorff-Larsen $\mathrm{K}$, Rasmussen MS, Lanng $\mathrm{C}$, Wallin L, Iversen $\mathrm{LH}$ Gramkow CS, Okholm M, Blemmer T, Svendsen PE, Rottensten $\mathrm{HH}_{\text {, }}$ Thage B, Riis J, Jeppesen IS, Teilum D, Christensen AM, Graungaard B, Pott F, Danish Study Group on Perioperative Fluid Therapy: Effects of intravenous fluid restriction on postoperative complications: comparison of two perioperative fluid regimens randomized assessor-blinded multicenter trial. Ann Surg 2003, 238:641-648.

34. McArdle GT, McAuley DF, McKinley A, Blair P, Hoper M, Harkin DW Preliminary results of a prospective randomized trial of restrictive versus standard fluid regime in elective open abdominal aortic aneurysm repair. Ann Surg 2009, 250(1):28-34.

35. Hamilton MA, Cecconi M, Rhodes A: A systematic review and meta-analysis on the use of preemptive hemodynamic intervention to improve postoperative outcomes in moderate and high-risk surgical patients. Anesth Analg 2011, 112(6):1392-1402.
36. Della Rocca G, Pompei L: Goal-directed therapy in anesthesia: any clinical impact or just a fashion? Minerva Anestesio/ 2011, 77(5):545-553.

37. Doherty M, Buggy DJ: Intraoperative fluids: how much is too much? $\mathrm{Br} J$ Anaesth 2012, 109:69-79.

38. Lambert KG, Wakim JH, Lambert NE: Preoperative fluid bolus and reduction of postoperative nausea and vomiting in patients undergoing laparoscopic gynecologic surgery. AANA J 2009, 77:110-114.

39. Maharaj CH, Kallam SR, Malik A, Hassett P, Grady D, Laffey JG: Preoperative intravenous fluid therapy decreases postoperative nausea and pain in high risk patients. Anesth Analg 2005, 100(3):675-682.

40. Moretti EW, Robertson KM, El-Moalem H, Gan TJ: Intraoperative colloid administration reduces postoperative nausea and vomiting and improves postoperative outcomes compared with crystalloid administration. Anesth Analg 2003, 96(2):611-617.

41. Vallet B, Blanloeil Y, Cholley B, Orliaguet G, Pierre S, Tavernier B: Guidelines for perioperative haemodynamic optimization. Ann Fr Anesth Reanim 2013, 32(10):e151-e158.

42. Dalfino L, Giglio MT, Puntillo F, Marucci M, Brienza N: Haemodynamic goal-directed therapy and postoperative infections: earlier is better: a systematic review and meta-analysis. Crit Care 2011, 15:R154

43. Mythen MG, Swart M, Acheson N, Crawford R, Jones K, Kuper M, McGrath JS, Horgan A: Perioperative fluid management: consensus statement from the enhanced recovery partnership. Perioper Med (Lond) 2012, 1:2

44. Powell-Tuck J, Gosling P, Lobo DN, Allison SP, Carlson GL, Gore M, Lewington AJ, Pearse RM, Mythen M: British consensus guidelines on intravenous fluid therapy for adult surgical patients - GIFTASUP. 2008. Available from: http://www.ics.ac.uk/ics-homepage/guidelines-standards/. (Accessed 12 June 2014).

45. Vallet B, Blanloeil Y, Cholley B, Orliaguest G, Pierre S, Tavernier B: Guidelines for perioperative haemodynamic optimization. Ann Fr Anesth Reanim 2013, 32:454-462.

46. Gustafsson UO, Scott MJ, Schwenk W, Demartine N, Roulin D, Francis N, McNaught CE, Macfie J, Liberman AS, Soop M, Hill A, Kennedy RH, Lobo DN, Fearon K, Lijungqvist $\mathrm{O}$ : Guidelines for perioperative care in elective colonic surgery: enhanced recovery after surgery (ERAS) society. World J surg 2013, 37:259-284.

47. McKendry M, McGloin H, Saberi D, Caudwell L, Brady AR, Singer M: Randomised controlled trial assessing the impact of a nurse delivered, flow monitored protocol for optimisation of circulatory status after cardiac surgery. BMJ 2004, 329(7460):258.

48. Mythen MG, Webb AR: Perioperative plasma volume expansion reduces the incidence of gut mucosal hypoperfusion during cardiac surgery. Arch Surg 1995, 130:423-429.

49. Sinclair S, James S, Singer M: Intraoperative intravascular volume optimisation and length of hospital stay after repair of proximal femoral fracture: randomised controlled trial. Br Med J 1997, 315:909-912.

50. Venn R, Steele A, Richardson P, Poloniecki J, Grounds M, Newman P. Randomized controlled trial to investigate influence of the fluid challenge on duration of hospital stay and perioperative morbidity in patients with hip fractures. Br J Anaesth 2002, 88:65-71.

51. Noblett SE, Snowden CP, Shenton BK, Horgan AF: Randomized clinical trial assessing the effect of Doppler-optimized fluid management on outcome after elective colorectal resection. Br J Surg 2006, 93:1069-1076.

52. Gan TJ, Soppitt A, Maroof M, El-Moalem H, Robertson KM, Moretti E, Dwane P, Glass PS: Goal-directed intraoperative fluid administration reduces length of hospital stay after major surgery. Anesthesiology 2002, 97:820-826.

53. Conway DH, Mayall R, Abdul-Latif MS, Gilligan S, Tackaberry C: Randomised controlled trial investigating the influence of intravenous fluid titration using oesophageal Doppler monitoring during bowel surgery. Anaesthesia 2002, 57:845-849.

54. Wakeling HG, McFall MR, Jenkins CS, Woods WG, Miles WF, Barclay GR, Flaming SC: Intraoperative oesophageal Doppler guided fluid management shortens postoperative hospital stay after major bowel surgery. Br J Anaesth 2005, 95:634-642.

55. Agency for Healthcare Research and Quality: Esophageal Doppler ultrasound-based cardiac output monitoring for real-time therapeutic management of hospitalized patients: a review. 2014, http://www.cms. gov/Medicare/Coverage/DeterminationProcess/downloads/id45TA.pdf (accessed 12 June 2014). 
56. National Institute for Health and Clinical Excellence: CardioQ-ODM oesophageal Doppler monitor. Medical Technology Guide 3. 2011, http://www.nice.org.uk/nicemedia/live/13312/52624/52624.pdf (accessed 12 June 2014).

57. Sandham JD, Hull RD, Brant RF, Knox L, Pineo GF, Doig CJ, Laporta DP, Viner S, Passerini L, Devitt H, Kirby A, Jacka M: A randomized, controller trial of the use of pulmonary-artery catheters in high-risk surgical patients. N Engl J Med 2003, 48(3):5-14.

58. Wesseling KH, Jansen JRC, Settels JJ, Schreuder JJ: Computation of aortic flow from pressure in humans using a nonlinear, three-element model. J Appl Physiol 1993, 74:2566-2573.

59. Jonas MM, Tanser SJ: Lithium dilution measurement of cardiac output and arterial pulse waveform analysis: an indicator dilution calibrated beat-by-beat system for continuous estimation of cardiac output. Curr Opin Crit Care 2002, 8:257-261.

60. Sander M, Spies CD, Grubitzsch H, Foer A, Müller M, Von Heymann C: Comparison of uncalibrated arterial waveform analysis in cardiac surgery patients with thermodilution cardiac output measurements. Crit Care 2006, 10:R164

61. Østergaard M, Nielsen J, Nygaard E: Pulse contour cardiac output: an evaluation of the FloTrac method. Eur J Anaesthesiol 2009, 26:484-489.

62. Vetrugno L, Costa MG, Spagnesi L, Pompei L, Chiarandini P, Gimillaro I, Della RG: Uncalibrated arterial pulse cardiac output measurement in patients with moderately abnormal left ventricular function. J Cardiothorac Vasc Anesth 2011, 25(1):53-58.

63. Hofer CK, Senn A, Weibel L, Zollinger A: Assessment of stoke volume variation for prediction of fluid responsiveness using the modified FlowTrac and PiCCO plus system. Crit Care 2008, 12:R82.

64. Salzwedel C, Puig J, Carstens A, Bein B, Molnar Z, Kiss K, Hussain A, Belda J, Kirov MY, Sakka SG, Reuter DA: Perioperative goal-directed hemodynamic therapy based on radial arterial pulse pressure variation and continuous cardiac index trending reduces postoperative complications after major abdominal surgery: a multi-center, prospective, randomized study. Crit Care 2013, 17:R191.

65. Pearse RM, Harrison DA, MacDonald N, Gillies MA, Blunt M, Ackland G, Grocott MPW, Ahern A, Griggs K, Scott R, Hinds C, Rowan K, for the OPTIMISE Study Group: Effect of a perioperative, cardiac output-guided hemodynamic therapy algorithm on outcomes following major gastrointestinal surgery a randomized clinical trial and systematic review. JAMA 2014, 311(21):2181-2190.

66. Pearse R, Dawson D, Fawcett J, Rhodes A, Ground RM, Bennet ED: Early goal-directed therapy after major surgery reduces complications and duration of hospital stay. A randomised, controlled trial [ISRCTN38797445]. Crit Care 2005, 9:R687-R693.

67. Brandstrup B, Svendsen PE, Rasmussen M, Belhage B, Rodt SÅ, Hansen B, Møller DR, Lundbech LB, Andersen N, Berg V, Thomassen N, Andersen ST, Simonsen $L$ : Which goal for fluid therapy during colorectal surgery is followed by the best outcome: nearmaximal stroke volume or zero fluid balance? Br J Anaesth 2012, 109:191-199.

68. Morris C: Oesophageal Doppler monitoring, doubt and equipoise: evidence based medicine means change. Anaesthesia 2013, 68:677-683.

69. Hood JA, Wilson RJT: Pleth variabilità index to predict fluid responsiveness in colorectal surgery. Anesth Analg 2011, 113:1058-1063.

70. Monnet X, Guérin L, Jozwiak M, Bataille A, Julien F, Richard C, Teboul JL: Pleth variabilità index is a weak predictor of fluid responsiveness in patients receiving norepinephrine. Br J Anaesth 2013, 110:207-213.

71. Srinivasa S, Kahokehr A, Soop M, Taylor M, Hill AG: Goal-directed fluid therapy- a survey of anaesthetists in the UK, USA, Australia and New Zealand. BMC Anesthesiol 2013, 13:5.

72. Miller TE, Roche AM, Gan TJ: Poor adoption of hemodynamic optimization during major surgery: are we practicing substandard care? Anesth Analg 2011, 112(6):1274-1276.

73. Shoemaker WC, Appel PL, Kram HB, Waxman K, Lee TS: Prospective trial of supranormal values of survivors as therapeutic goals in high-risk surgical patients. Chest 1988, 94(6):1176-1186.

74. Morgan TJ: High-risk non-cardiac surgery - is supranormal oxygen delivery the answer? Crit Care Resusc 2000, 2:150-155.

75. Arulkumaran N, Corredor C, Hamilton MA, Ball J, Grounds RM, Rhodes A, Cecconi M: Cardiac complications associated with goal-directed therapy in high-risk surgical patients: a meta-analysis. Br J Anaesth 2014, 112(4):648-659.
76. Wenkui $Y$, Ning L, Jianfeng G, Weiqin L, Shaoqiu T, Zhihui T, Tao G, Juanjuan Z, Fengchang $X$, Hui S, Weiming Z, Jie-Shou L: Restricted perioperative fluid administration adjusted by serum lactate level improved outcome after major elective surgery for gastrointestinal malignancy. Surgery 2010, 147:542-552.

77. Nisanevich V, Felsenstein I, Almogy G, Weissman C, Einav S, Matot I: Effect of intraoperative fluid management on outcome after intrabdominal surgery. Anesth 2005, 103:25-32.

78. Holte K, Kehlet H: Fluid therapy and surgical outcomes in elective surgery: a need for reassessment in fast-track surgery. J Am Coll Surg 2006, 202(6):971-989.

doi:10.1186/1471-2253-14-62

Cite this article as: Della Rocca et al:: Liberal or restricted fluid administration: are we ready for a proposal of a restricted intraoperative approach? BMC Anesthesiology 2014 14:62.

\section{Submit your next manuscript to BioMed Central and take full advantage of:}

- Convenient online submission

- Thorough peer review

- No space constraints or color figure charges

- Immediate publication on acceptance

- Inclusion in PubMed, CAS, Scopus and Google Scholar

- Research which is freely available for redistribution

Submit your manuscript at www.biomedcentral.com/submit
C) Biomed Central 